\title{
Micro-grid powered by photovoltaic and micro turbine
}

\author{
Ph. Degobert ${ }^{1}$, S. Kreuawan ${ }^{2}$ and X. Guillaud ${ }^{2}$ \\ Laboratoire d'Electrotechnique et d'Electronique de Puissance de Lille (L2EP) \\ ${ }^{1}$ Ecole Nationale Supérieure d'Arts et Métiers, Centre d'Etudes et de Recherches, \\ 8 Boulevard Louis XIV, 59046 Lille Cedex, France \\ Phone: (33)320.622 229 - Fax: (33)320.622 750 - E-mail: philippe.degobert@lille.ensam.fr \\ ${ }^{2}$ Ecole Centrale de Lille, \\ Boulevard Paul Langevin, 59651 Villeneuve d'ascq, France \\ Phone: (33)320.335 387 - E-mail: Xavier.guillaud@ec-lille.fr
}

\begin{abstract}
In this paper, we propose to study the possibility of using a photovoltaic system combined with a high speed micro-turbine. This hybrid system can work as stand-alone system or grid connected system as it will be a part of a microgrid. Initially, we propose simple dynamic models of photovoltaic and micro turbine systems. Then, we carry out a comparison between simulations and measurements of the two systems. At last, simulation results show the effectiveness of the suggested hybrid system.
\end{abstract}

\section{Key words}

Micro-grid, hybrid system, photovoltaic, micro-turbine, distributed generation, simulation.

\section{Introduction}

The production of photovoltaic system can vary slowly (day-night cycle and season change) and quickly because of weather conditions such as the passage of clouds. The power fluctuation might cause problems of power quality. Moreover a grid connected photovoltaic system is considered as a negative load by the grid because of its uncontrollable characteristic. To reduce these problems, we can integrate a storage system which allows the energy management [1]. The hybrid system is another interesting solution. It is using two or more renewable energy sources such as wind and/or solar and it becomes more wildly used [2]. The hybrid system with at least one controllable source such as diesel generator or micro turbine can solve this problem. This distributed generator is interesting because, it allows high efficiency with cogeneration system, low emission and fuel flexibility.

This paper presents a dynamic-simulation study of a photovoltaic system and a micro turbine operating within a multi-machine network [1]. Each generator can be connected via a DC bus. Then, a single static converter is connecting this DC bus to the grid. In this work, we choose to connect it to the AC bus because the expansion of system is not limited by the rated power of the static converter. Figure 1 shows the studied hybrid system: a $17,3 \mathrm{kWp}$ photovoltaic system associated to a $28 \mathrm{~kW}$ Capstone micro-turbine. This PV-system is installed in the north of France at the L2EP-ENSAM of Lille since December 2004. It can work as a stand-alone system or a grid connected system as it will be a part of a micro-grid [1],[2]. A 28kW MTG will be settled in April 2006.

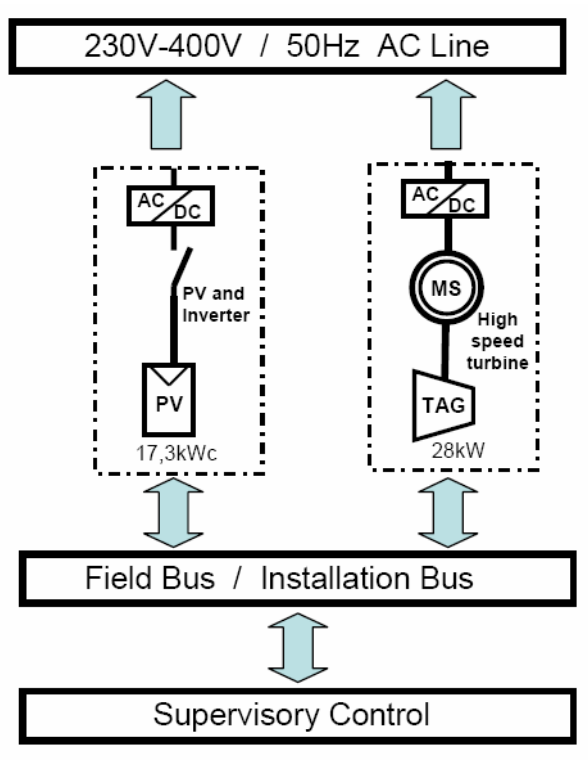

Figure 1. PV/MTG micro-grid control scheme.

\section{Photovoltaic system modelling}

\section{A. Description of the PV system}

The photovoltaic studied system, presented in figure 2, consists of 108 modules BP solar 3160 with power of $160 \mathrm{Wp}$ each. These modules are connected to a 3-phase grid via six inverters Fronius IG30 (one inverter connects 2 branches of 8 modules in parallel). In the first year of electric production, this $17,3 \mathrm{kWp} \mathrm{PV}$-system generated $13600 \mathrm{kWh}$ as shown in figure 3. 


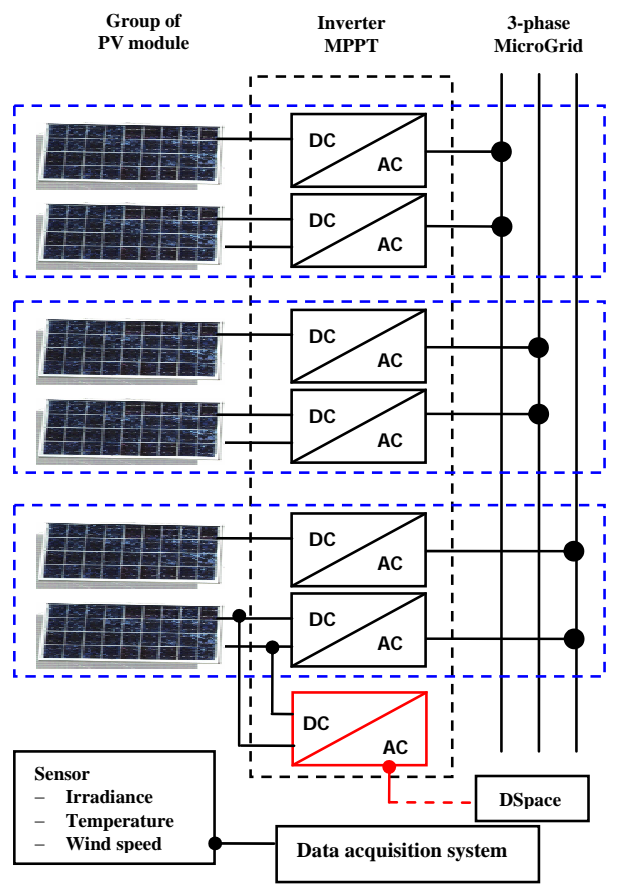

Figure 2. PV control scheme.

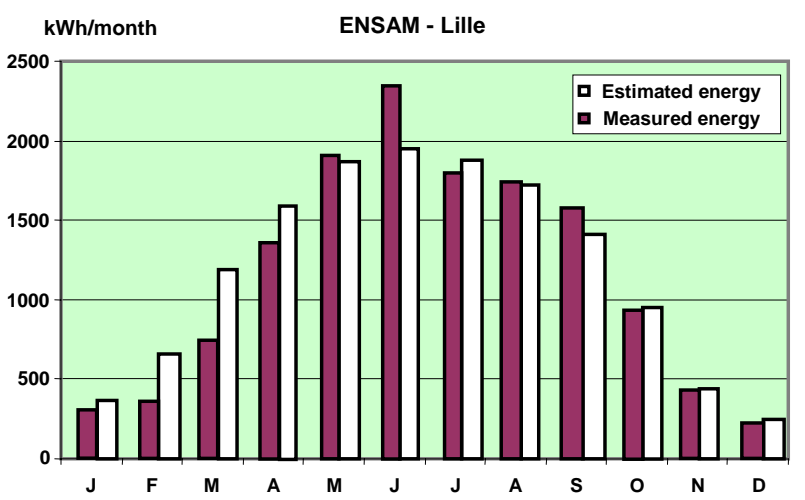

Figure 3. Photovoltaic energy produced in 2005.

\section{B. $P V$ modelling and simulation}

In a previous work, we have compared two models of photovoltaic modules: a classical one-diode model [18] and a simplified model [19]. Inputs of these models are the temperature and the irradiance. The simulated characteristics of the model suggested by W. Xiao and als. applied to the BP solar 3160 modules are shown in figure 4.
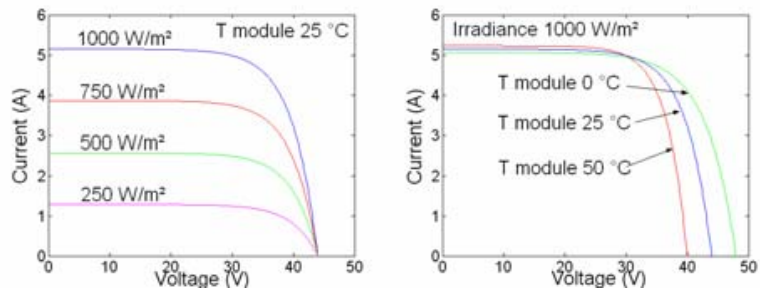

Figure 4. BP solar 3160 characteristic.

Figure 5 shows the accuracy of the modelling for one of the six PV-inverters. We can notice that the difference between measurement and simulation is negligible.

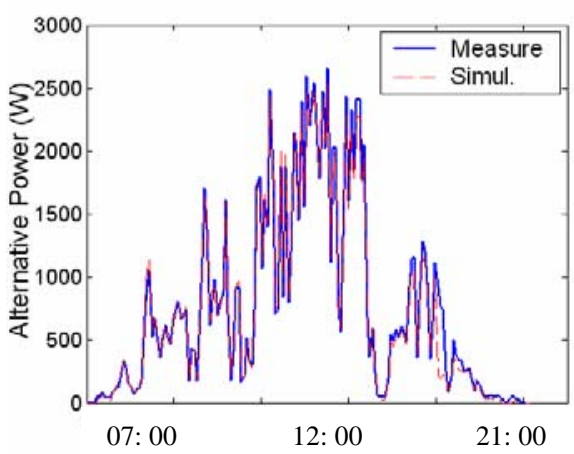

Figure 5. Photovoltaic power on May $7^{\text {th }}, 2005$.

\section{Capstone Micro-turbine modelling}

\section{A. Description of the Micro-turbine generator}

For this application, we have chosen a Capstone Micro Turbine Generator, Model C330, (MTG) [6]. The device is a recuperated single stage radial flow compressor and turbine on a single shaft integral with the generator. This MTG is composed of the following subassemblies: a Turbo Generator (TG); a two-way Frequency Converter AC-DC-AC (FC); a Fuel Control System (FCS); and a Digital Power Controller (DPC). The block diagram for the power source based on Capstone $28 \mathrm{~kW}$ MicroTurbine technology is represented in Figure 6.

The Turbo Generator includes a Gas Compressor (GC), a Combustion Chamber (CC), a Turbine (T), a Heat Recuperator (HR), and a High-speed Generator (PMSM). This model of Capstone MTG is equipped with a low NOx combustion engine and an internal natural gas compressor. These rotating components are mounted on a single shaft supported by air bearings. Air from the generator then flows into the GC where it is pressurized and forced into the cold side of the HR. Exhaust heat is used to preheat the air before it enters the Combustion Chamber and thus reduce fuel consumption by about 50 percent. Then, the CC mixes the heated air with fuel and burns it. This mixture expands through the turbine, which drives the GC and generator at up to 96,000 RPM. The combusted air is then exhausted through the recuperator before being discharged at the exhaust outlet.

The used High-speed Generator is a two-pole Permanent Magnet Synchronous Machine (PMSM) with a nonsalient rotor. This PMSM generator is cooled by the air flow into the Micro-turbine, and the output of the generator is a variable-voltage system, variablefrequency AC power at up to $1,600 \mathrm{~Hz}$. At 1,600 Hertz (96,000 RPM), the machine output power is $28 \mathrm{~kW}$ and its terminal line-to-line voltage is $400 \mathrm{~V}$.

Two back-to-back power converters are used to generate $50 \mathrm{~Hz}$ quantities to the grid. Generally, a one-way frequency converter AC-DC-AC with a diode rectifier is used to interface the high frequency alternator and the DC bus [13]. The Capstone C330 model uses a two-way frequency converter AC-DC-AC: the power structures of 
both electronic converters are identical [6]. It can be shown that for this model of MTG, the generated current harmonics are adequately attenuated by the machine inductance and by the grid LC-filter [7],[8].

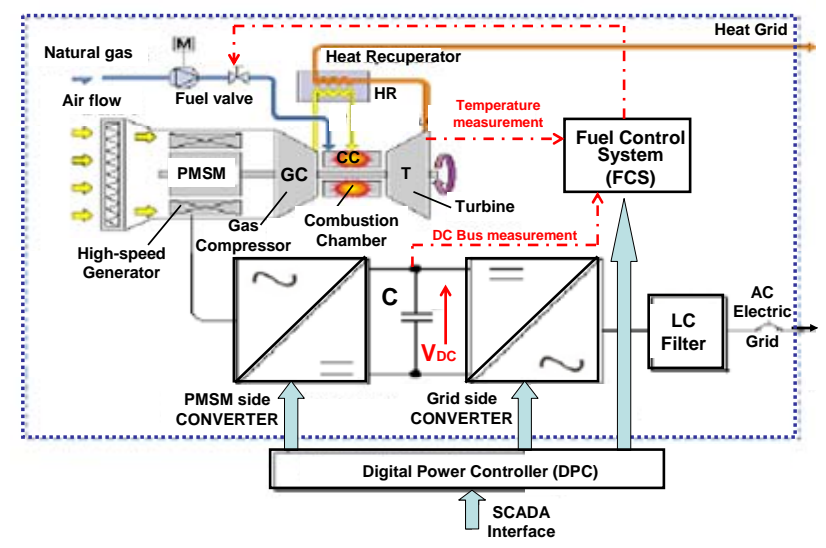

Figure 6. Gas micro-turbine generator.

A micro-turbine requires about $15-20$ seconds for a $50 \%$ change in power output. The figure 7 shows the Capstone M330 Micro Turbine responses to a step change in the fuel valve [7].

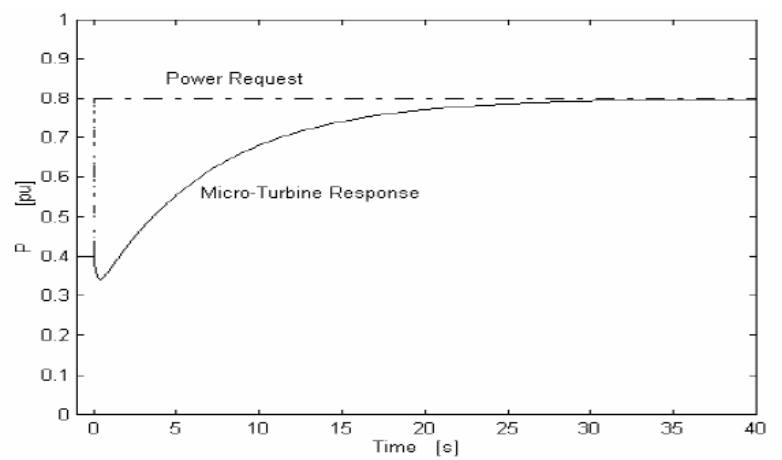

Figure 7. Capstone C330 Micro turbine Step Change Response.

To remove such limitations in the dynamics of the power sources some form of storage system is necessary at the $\mathrm{AC}$ or DC bus to cope with instantaneous changes in power demand. In an island mode, this is critical in the case of sensitive loads, because micro-grids will be incapable of meeting load requirements if a storage system is not included [4].

\section{B. MTG modelling and simulation}

The dynamic modelling and simulation of the Microturbine have been discussed in details in many literatures [3]-[17]. We propose a short review of most of them. In 1983, a combustion gas turbine model was developed to represent the gas turbine dynamics [9]. In 1993, a working group proposed an extension of this work, including speed, temperature, acceleration and fuel controls [10]-[12]. However this work deals with heavyduty gas turbines. H. Nikkhajoei and M. R. Iravani proposed a model for the MTG [15] based on the Nern's non-linear long term model of the Gas Turbo Generator [14]. In [3], the authors developed a generic model of a grid-connected micro-turbine converter.
In [13], a linearized model of the micro-turbine was adopted and compared to a first order transfer function. In [16], the authors were interested in analyzing thermodynamics and the electromechanical stability of micro turbines and [17] focused on the dynamic behaviour of a split shaft micro turbine.

After analysing these different modelling, we concluded that in certain conditions, it was possible to use a simple first order adaptive model with the variations of power. This is the model used in this work.

Table I presents the identified rise time value of output power. Figure 8 compares between the measured [7] and the simulated results [20] of Capstone C330 Micro turbine step power change response.

TABLE I. - MTG rise time value of output power

\begin{tabular}{|c|c|c|c|c|c|c|}
\hline$\Delta \mathbf{P} / \mathbf{P}$ & $\mathbf{5 0 0 0}$ & $\mathbf{1 0 0 0 0}$ & $\mathbf{1 5 0 0 0}$ & $\mathbf{2 0 0 0 0}$ & $\mathbf{2 5 0 0 0}$ & $\mathbf{2 8 0 0 0}$ \\
\hline $\mathbf{- 2 8 0 0 0}$ & 50 & 50 & 50 & 50 & 50 & 50 \\
\hline $\mathbf{- 1 5 0 0 0}$ & 52 & 52 & 52 & 39 & 26 & 18 \\
\hline $\mathbf{- 1 0 0 0 0}$ & 44 & 44 & 28 & 12 & 15 & 16 \\
\hline $\mathbf{- 5 0 0 0}$ & 36 & 28 & 22 & 12 & 12 & 10 \\
\hline $\mathbf{0}$ & 37 & 25 & 24 & 15 & 13 & 9 \\
\hline $\mathbf{5 0 0 0}$ & 38 & 22 & 26 & 18 & 14 & 8 \\
\hline $\mathbf{1 0 0 0 0}$ & 38 & 38 & 40 & 42 & 23 & 12 \\
\hline $\mathbf{1 5 0 0 0}$ & 38 & 38 & 38 & 30 & 21 & 16 \\
\hline $\mathbf{2 8 0 0 0}$ & 49 & 49 & 49 & 49 & 49 & 49 \\
\hline
\end{tabular}

Capstone LP Stand-alone Tests 10/25/2001

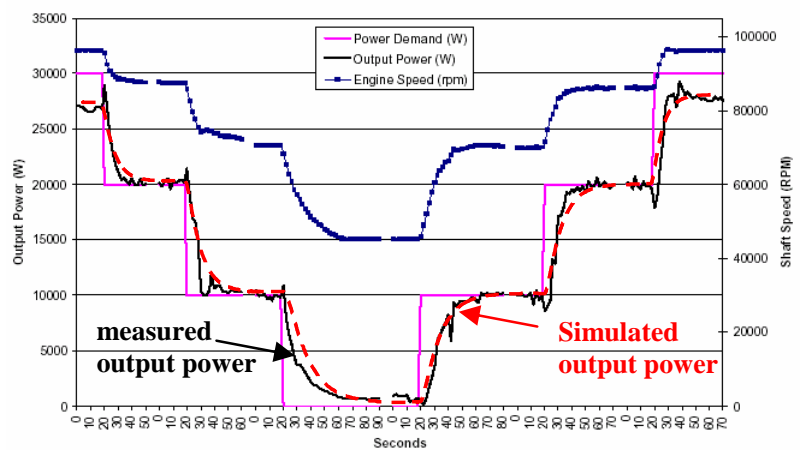

Figure 8. comparison between measured and simulated results of C330 Micro turbine step power change response.

\section{Hybrid Photovoltaic/Microturbine system}

\section{A. Description of the PV/MTG}

The association of a photovoltaic system and a micro turbine allows the energy management:

- In a stand-alone system, the difference between the photovoltaic energy and loads is adjusted by the micro turbine which means energy storage system is not necessary.

- In a grid-connected system, in which the energy is controllable, this system can be considered by the grid as a small power plant, not only as a negative load. 


\section{B. Simulation of the PV/MTG}

The Matlab-Simulink model of PV/MTG micro-grid is shown in figure 9. Inputs of these models are the temperature, the irradiance and the power demand.

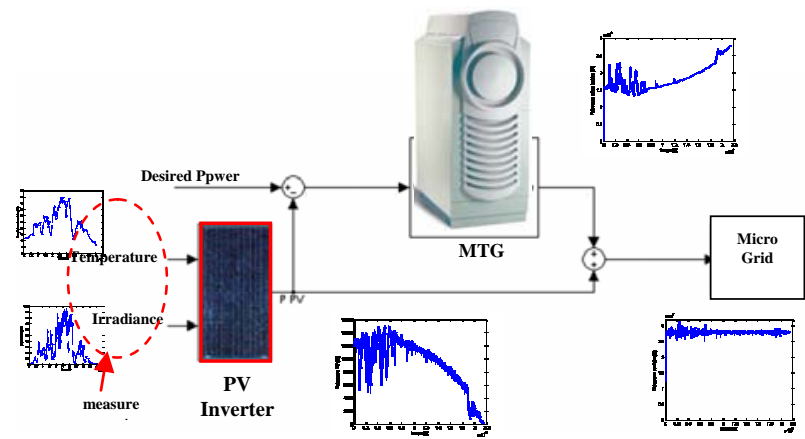

Figure 9. Matlab model of the PV/MTG micro-grid.

Figure 10 shows the various powers with an applied reference electric power of $28 \mathrm{~kW}$. The simulated results prove the effectiveness of the proposed solution. We can notice that the MTG practically compensate all the PV fluctuations of power. Nevertheless, it is necessary to reduce the fast fluctuations of power in the case of sensitive loads.
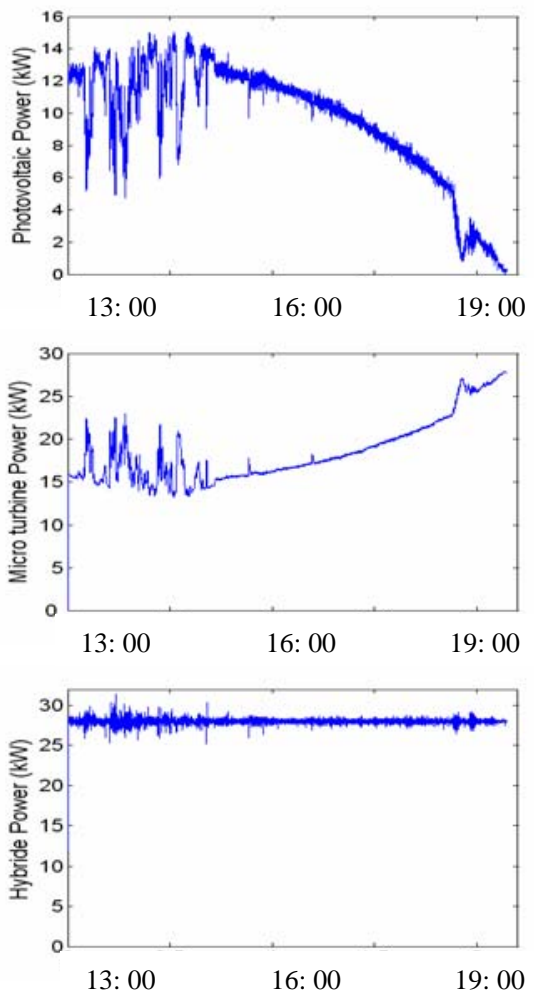

Figure 10. Power of PV/MTG micro-grid.

\section{Conclusion}

Initially, we carried out a simple and effective modelling of the PV and MTG generators. The effectiveness of the proposed hybrid system was verified by simulation. Lastly, we showed that short-term storage was necessary to reduce the fasts fluctuations of power in the case of sensitive loads. In future work, we propose to use supercapacitors to reduce them (ANR French project).

\section{References}

[1] Abu-Sharkh S. et al. "Can microgrids make a major contribution to UK energy supply? Renewable and Sustainable Energy Reviews 10 (2006) 78-127.

[2] R. Lasseter, A. Akhil, C. Marnay, J. Stephens, J. Dagle, R. Guttromson, A. Sakis Meliopoulous, R. Yinger, and J. Eto, "Integration of Distributed Energy Resources - The MicroGrid Concept”. CERTS MicroGrid Review Feb 2002.

[3] R. Lasseter, "Dynamic models for micro-turbines and fuel cells" Power Engineering Society Summer Meeting, 2001. IEEE, pp.: 761-766 vol.2.

[4] R. Lasseter, K. Tomsovic and P. Piagi, "Scenarios for Distributed Technology Applications with Steady State and Dynamic Models of Loads and Micro-Sources" CERTS Report, April 2000.

[5] S. F. Gillette, "CHP Case Studies - Saving Money and Increasing Security”, Capstone Turbine Corporation.

[6] http://www.capstoneturbine.com

[7] R.J. Yinger, "Behavior of Capstone and Honeywell Micro turbine Generators During Load Changes" CERTS Report LBNL-49095, July 2001.

[8] O.Fethi, L.-A. Dessaint, K. Al-Haddad, "Modeling and simulation of the electric part of a grid connected microturbine" Power Engineering Society General Meeting, 2004. IEEE 6-10 June 2004 Page(s): 2212 - 2219 Vol.2.

[9] W. I. Rowen, "Simplified mathematical representation of heavy duty gas turbine" ASME Trans. 1983, Vol.105, №1.

[10] L. N. Hannett, A. Khan, "Combustion turbine dynamic model validation from tests" IEEE Trans. On Power Systems, 1993, Vol. 8, N¹.

[11] Working Group on Prim Mover and Energy Supply Models for System Dynamic Performance Studies, "Dynamic models for combined cycle plants in power system studies", IEEE Trans. On Power Systems, 1994, Vol. 9, $\mathrm{N}^{\circ} 3$.

[12] L. N. Hannett, G. Jee, B. Fardanesh, "A governor turbine model for a twin shaft combustion turbine" IEEE trans. On Power Systems, 1995, Vol.10, N¹.

[13] A. Al-Hinai, A. Feliachi, "Dynamic model of a microturbine used as a distributed generator", System Theory, Proceedings of the Thirty-Fourth South-eastern Symposium on 18-19 March 2002, pp. 209-213;

[14] H. J. Nern, H. Kreshman, F. Fischer, HA. Nour Eldin, "Modelling of the long term dynamic performance of a gas turbo generator set", Proceedings of IEEE, Conf. on Control applications, 1994, Vol. 1, pp. 491-496.

[15] H. Nikkhajoei, M. R. Iravani, "Modelling and analysis of a micro-turbine generation system" Power Engineering Society Summer Meeting, 2002 IEEE, pp. 167-169 vol.1.

[16] A. Al-Hinai, K. Schoder, A. Feliachi "Control of gridconnected splitshaft microturbine distributed generator" System Theory, 2003. Proceedings of the 35th Southeastern Symposium, pp. 84-88

[17] G. Joos, B. T. Ooi, D. McGillis, F. D. Galiana, R. Marceau, "The potential of distributed generation to provide ancillary services" Power Engineering Society Summer Meeting, 2000. IEEE, pp. 1762 -1767.

[18] H.S. Rauschenbach, "Solar Cell Array Design Handbook", Van Nostrand-Reinhold, NY, 1980.

[19] W. Xiao, W.G. Dunford, A. Capel, “A novel modeling method for photovoltaic cells", IEEE Power Electronics Specialists Conference, Aachen, Allemagne, 2004.

[20] S. Kreuawan, "Study of a hybrid micro-grid associating a photovoltaic power station and a gas micro-turbine" (text in French), Master project E2D2, June 2005, Lille, France. 